Castillo Gaitán, B. (2022). EL PATRIMONIO CULTURAL COMO RECURSO PEDAGOGICO EN LA

REHABILITACIÓN DE PERSONAS CON PROBLEMAS DE ADICCIÓN A LAS DROGAS. Revista Herencia, 35(1), enero-junio, 45-56.

\title{
EL PATRIMONIO CULTURAL COMO RECURSO PEDAGÓGICO EN LA REHABILITACIÓN DE PERSONAS CON PROBLEMAS DE ADICCIÓN A LAS DROGAS
}

Cultural heritage as a pedagogical resource in the rehabilitation of people with drug addiction problems

\author{
Bernardo Castillo Gaitán \\ Escuela de Estudios Generales, Universidad de Costa Rica, Costa Rica \\ bernardo.castillo@ucr.ac.cr
}

Recibido: 22-09-2021

Aprobado: 04-11-2021

Docente en la Sección de Filosofía de la Escuela de Estudios Generales de la Universidad de Costa Rica; Coordinador de la Sección de Seminarios de Realidad Nacional, Diplomado en Planificación Comunitaria, Diplomado en Prevención de Adicción a las Drogas en Ambiente Universitario, Bachiller en Filosofía y Humanidades, Licenciado en Teología Pastoral, Master en Ciencias de la Educación, estudiante del Doctorado en Filosofía de la Universidad de Costa Rica.

\section{RESUMEN}

Este artículo presenta una experiencia en la que el Patrimonio Cultural es recurso pedagógico para la rehabilitación de personas con problemas de adicción a las drogas que se desarrolla en el Centro de Rehabilitación de Adictos a las drogas denominado Rostro de Jesús y se ilustra el proceso educativo - creativo que realizan los internos para la conmemoración de los 200 años de vida independiente.

Palabras clave: patrimonio cultural; adicción; rehabilitación

\section{ABSTRACT}

This article presents an experience in which the Cultural Heritage is a pedagogical resource for the rehabilitation of people with drug addiction problems that takes place in the Rehabilitation Center for Drug Addicts called Rostro de Jesús and illustrates the educational-creative process carried out by the interns for the commemoration of 200 years of independent life.

Keywords: cultural patrimony; addiction; rehabilitation 
Revista Herencia, Vol. 35 (1), enero-junio, 2022.

\section{Introducción}

La expresión adicto o adicta a las drogas pone el énfasis más en el consumo de sustancias psicoactivas que en la humanidad de quien sufre esta situación. El proceso de rehabilitación de personas con problemas de adicción a las drogas, al que se hace referencia en este artículo, parte desde el ser integral de la persona y considera que la principal dificultad consiste en la pérdida del sentido de vida, lo que genera un vacío existencial que se traduce en depresión, ansiedad y frustración.

Se considera que la adicción a las drogas es un problema social que se aborda por medio de programas educativos en valores humanos como la tolerancia, la estima, el respeto a sí mismo y a los demás, pero principalmente por medio de la educación a la dignidad (Cañas 2008). El patrimonio cultural, como expresión de humanidad que se desarrolló en el pasado como herencia para referirse a la identidad en el presente, es fuente para preparar un futuro sin desesperarse $y$, por lo tanto, una herramienta para enseñar a vivir a quienes han perdido la esperanza para hacerlo (Leyva, 2015). No se presenta al patrimonio cultural como una medicina, sino como un tema que debe ser incorporado como un recurso para la educación de personas que acuden a los programas de atención de personas adictas a las drogas, como se expone en el presente artículo.

\section{Desarrollo}

El Rostro de Jesús, fundado en noviembre del 1997, es una organización no gubernamental, sin fines de lucro reconocida bajo la figura jurídica de asociación con declaratoria de institución de bienestar social y de interés público. Está ubicado en el distrito Canoas del Cantón Central de la Provincia de Alajuela. Tiene capacidad para atender 52 pacientes, hombres en edades de 21 a 65 años. Su principal característica es que es el único centro del país atendido por personas no adictas a las drogas y donde importa la persona como tal, independientemente de si su estado es de tristeza o de alegría.

Las adicciones degradan a la persona en casi todas las áreas de su vida, por lo que un programa de atención debe favorecer la recuperación integral, restaurando su salud física, espiritual, emocional y social. Lo anterior, plantea la necesidad de ofrecer un programa dinámico y equilibrado donde el residente encuentre tranquilidad para evaluar su vida presente y plantearse un futuro mejor al facilitar un acercamiento y posteriormente el reencuentro con la familia, el trabajo, la sociedad (Mora, 2018).

La metodología que se sigue para la atención es la construcción de una forma particular de hacer comunidad terapéutica, partiendo de que el problema a tratar no es la droga, sino la persona que obstaculiza el desarrollo de su dignidad humana (Mora, 2018). La intervención terapéutica no hace exclusivas las técnicas de eliminar el consumo de sustancias, si no se interviene a la persona en todas sus dimensiones: social, política, económica, religiosa y cultural.

El desarrollo del programa de rehabilitación se realiza bajo el principio de la educación inclusiva y la dimensión cultural es fundamental para recuperar el carácter creativo de la persona y por medio de actividades artísticas se logra evocar la expresión más íntima y personal. Es en la dimensión cultural del programa de atención donde el patrimonio 
Revista Herencia, Vol. 35 (1), enero-junio, 2022.

representa un recurso pedagógico transformador de vida de las personas (Maraña y Revert, 2020) y de suma importancia para aprender a ver el pasado como herencia de conocimiento y no como acontecimiento negativo con el deseo de querer transformarlo, pero con la imposibilidad de poder lograrlo. El patrimonio cultural es de gran ayuda para vivir el presente, demostrando que es el único momento de la vida que puede ser transformado porque se toma posesión del ser propio y de las cosas.

La rehabilitación de una persona adicta a la droga es una tarea que consiste en la reconstrucción de las relaciones humanas deterioradas causada por la desvalorización de su ser como personas (Sissa, 2000). La institución tiene como política no dar recetas ni consejos, sino que busca formas creativas para que la persona que sufre el flagelo de la adicción a la droga descubra el valor que posee. En este sentido, el patrimonio cultural es de gran ayuda para la rehabilitación porque permite la construcción social que se refleja en las obras artísticas de un pueblo (Leyva, 2015). Es también "el conjunto de valores que dan sentido a la vida, es decir, las obras materiales y no materiales que expresan la creatividad de ese pueblo" (UNESCO, 1982 p. 3) y la institución, en su programa de atención, ha incorporado la elaboración de manualidades que representen edificios patrimoniales y hechos de la historia del país en los que se evidencian los valores de las personas al adquirir el deseo imperante de vivir humanamente, ya que el

\footnotetext{
...patrimonio no está solo constituido por aquellos objetos del pasado que cuentan con un reconocimiento oficial, sino por todo aquello que nos remite a nuestra identidad. El concepto integral de patrimonio tiene como dimensión la globalidad del territorio y sus habitantes; como objetivo último, la calidad de vida consecuencia de un desarrollo económico y social sostenible; su metodología es la gestión integral de los recursos patrimoniales a partir de estrategias territoriales. (García Cuetos, 2014, p 18-19)
}

Si el patrimonio cultural remite a la identidad de las personas, quiere decir que es una forma de volver al punto de partida de la condición humana, a su originalidad, como un ser que crea para cultivarse y, por esta razón, en el proceso de rehabilitación de personas

\footnotetext{
...es fuente de inspiración para la creatividad y la innovación, que generan los productos culturales contemporáneos y futuros. El patrimonio cultural encierra el potencial de promover el acceso a la diversidad cultural y su disfrute. Puede también enriquecer el capital social conformando un sentido de pertenencia, individual y colectivo, que ayuda a mantener la cohesión social y territorial. Por otra parte, el patrimonio cultural ha adquirido una gran importancia económica para el sector del turismo en muchos países, al mismo tiempo que se generaban nuevos retos para su conservación (UNESCO, 2021)
}

La importancia de incorporar actividades educativas fundadas en el patrimonio cultural, le permite a la persona que está en el programa de rehabilitación pensar en su origen con el propósito de disminuir paulatinamente la cultura nómada de sobrevivencia y dar el paso hacia la convivencia; según Hernández (2012), el patrimonio cultural ayuda a recuperar la propia esencia del ser humano y, al relacionarlo con la educación de los programas de rehabilitación de personas con problemas de adicción a las drogas, el patrimonio cultural se asume en un

instrumento necesario e imprescindible para la comprensión y difusión de esa nueva ética mundial, lo convierte en una herramienta estratégica indispensable para el futuro de la Humanidad, junto con su valor determinante como soporte de los programas de progreso sostenible, que también hemos revisado (García Cuetos, 2014, p. 165) 
A través de patrimonio cultural se genera un proceso participativo de reflexión y de análisis de la realidad que tiene como objetivo la toma de conciencia por parte de los usuarios que reciben el programa de rehabilitación, para transformación de su propia vida y de la sociedad donde habitan (Alberti, 2010).

El proceso de la confección de las maquetas que representan edificios, paisajes o símbolos patrimoniales de Costa Rica, da inicio 45 días antes de la celebración del 14 y 15 de setiembre. Los usuarios son divididos en siete grupos, uno por cada provincia; en primer lugar, debe hacer una investigación bibliográfica relacionada con las características de cada una ellas. Durante el mes de agosto, por parte del trabajador Social y la Terapeuta ocupacional, reciben un taller relacionado con las fiestas patrias, las indicaciones relacionadas con el trabajo en equipo, los horarios de trabajo, el material por utilizar y cómo resolver en equipo las dificultades que puedan presentarse.

A continuación, se ilustra un hecho concreto de la incorporación del patrimonio cultural para educar a las personas adictas a las drogas en el marco de la celebración del bicentenario de la independencia de Costa Rica ya que el patrimonio cultural cívico es memoria como símbolo de cohesión social, de identidad y de respeto a la comunidad (Pérez, Amescua y Arizpe, 2011).

Imagen 1. Investigación sobre la provincia correspondiente

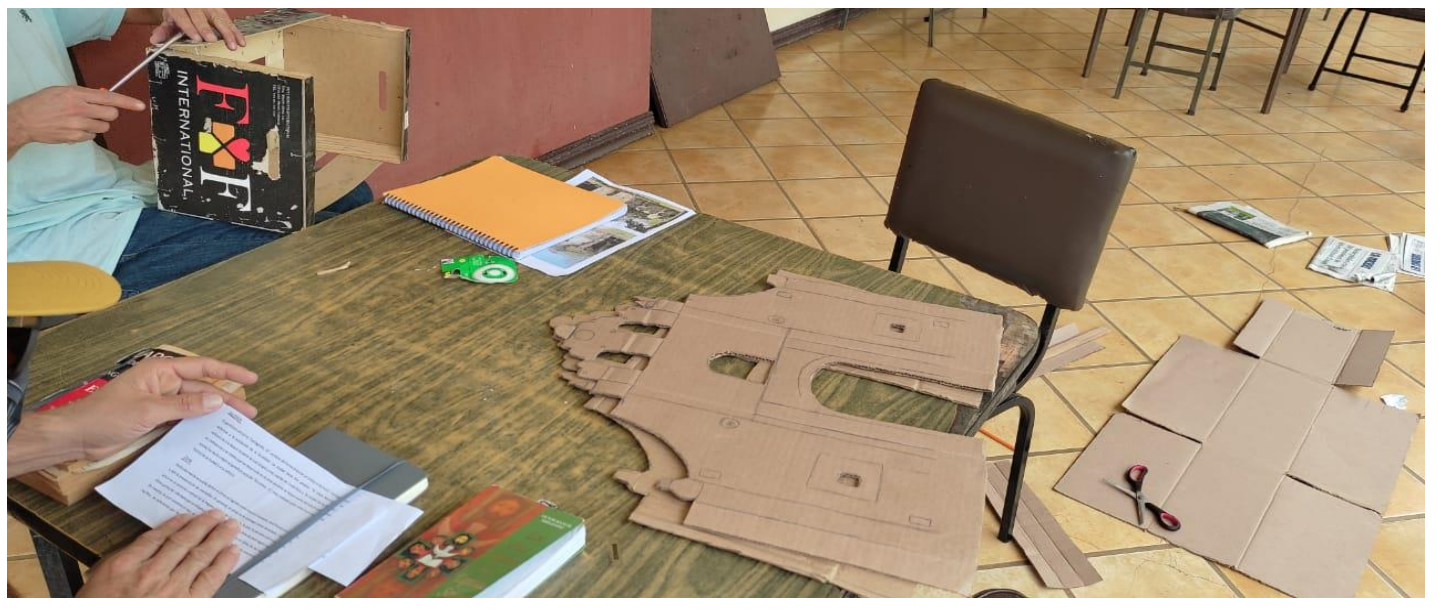

Fuente: Asociación Rostro de Jesús 2021

La figura 1 ilustra a dos usuarios estudiando información relacionada con la provincia de Cartago. Este proceso lo realiza cada uno de los siete grupos. Lo que se procura es que adquieran interés por la lectura, por la investigación y el desarrollo de la discusión respetuosa de un tema que edifique su dignidad como persona.

Imagen 2. Preparación de materiales 
Revista Herencia, Vol. 35 (1), enero-junio, 2022.

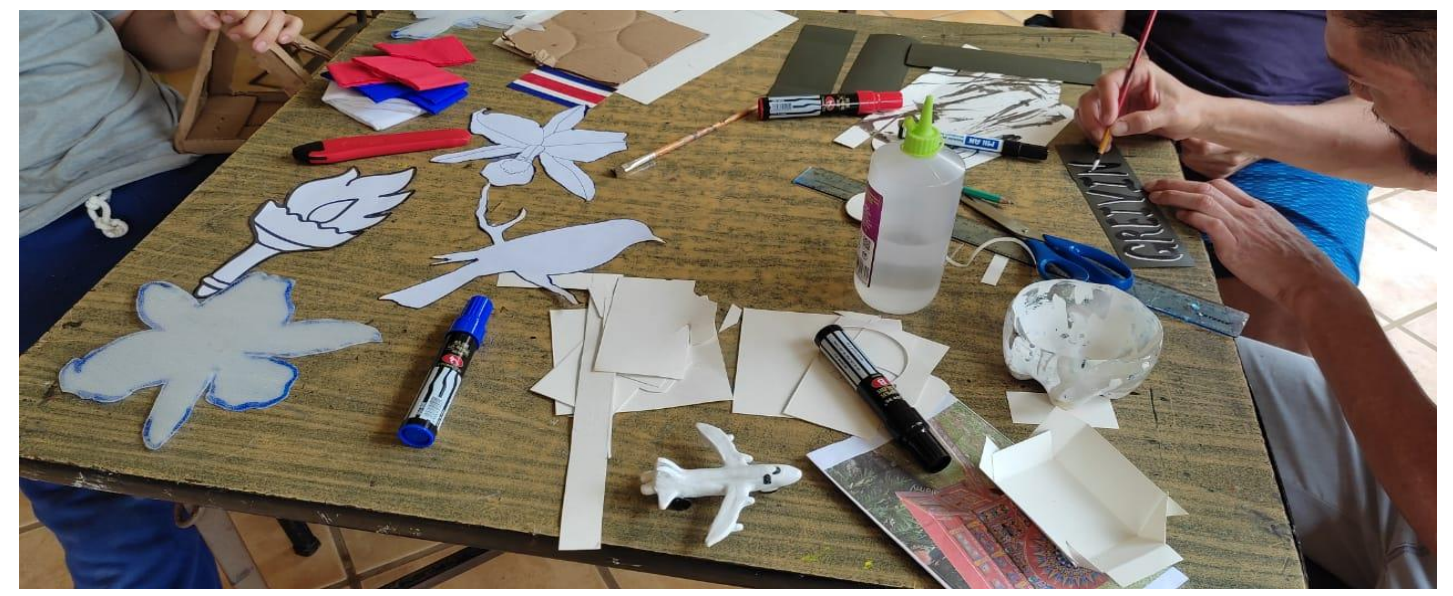

Fuente: Asociación Rostro de Jesús 2021

Imagen 3. Preparación de materiales

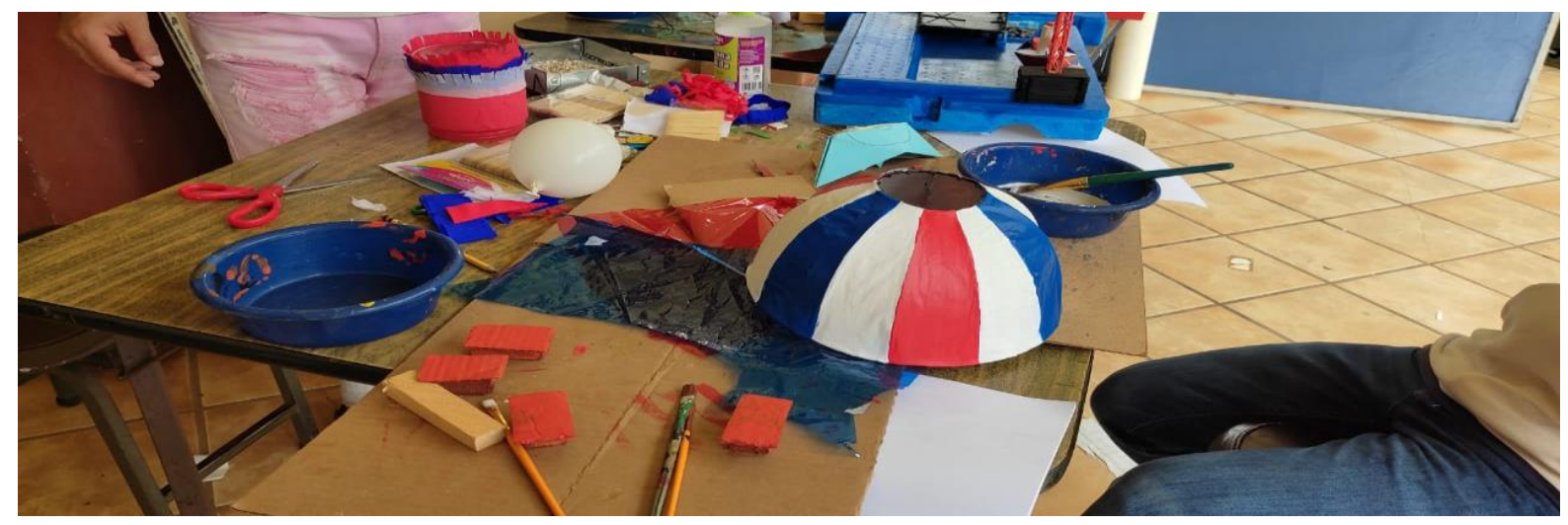

Fuente: Asociación Rostro de Jesús 2021

Imagen 4. Preparación de materiales 


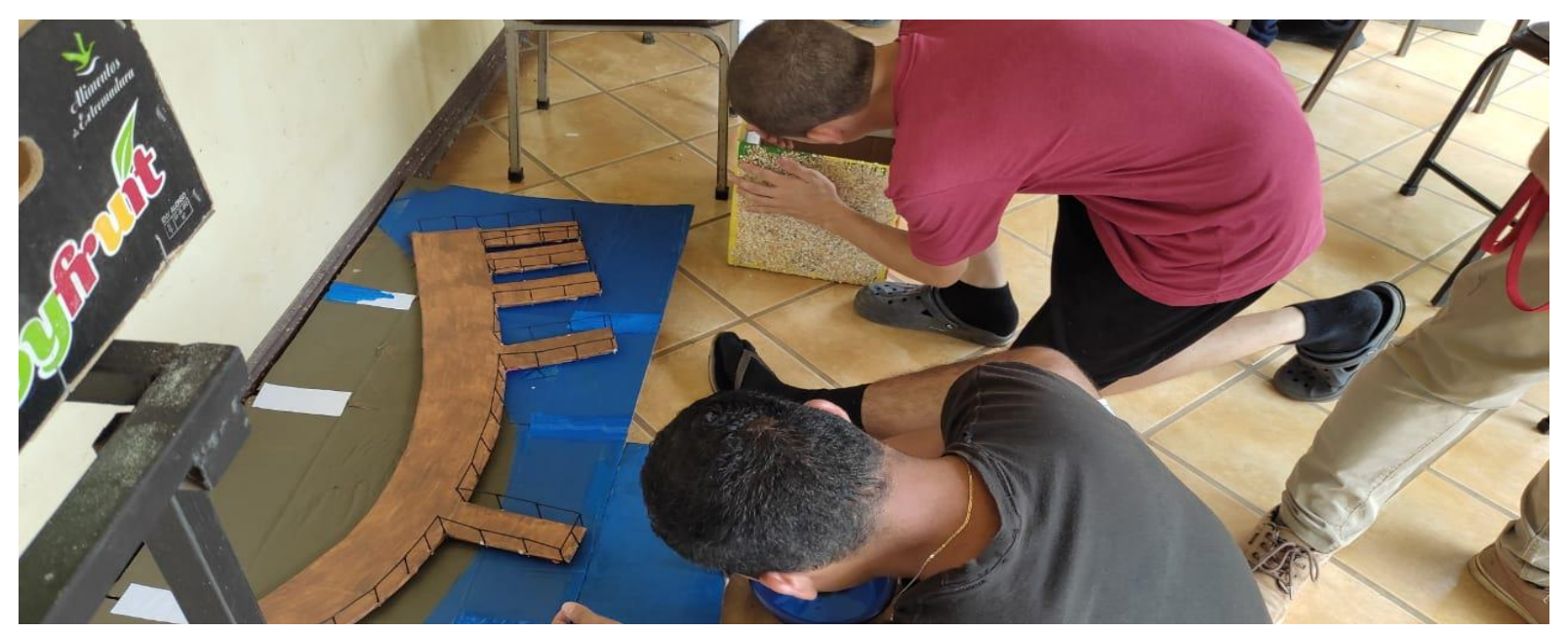

Fuente: Asociación Rostro de Jesús 2021

En las imágenes 2, 3, y 4 se ilustra la preparación de los materiales para la construcción de las maquetas. En este espacio se aprende a trabajar en equipo, a respetar el tiempo de los procesos, a respetar los límites, a cumplir un horario de trabajo, a pedir ayuda, a compartir las habilidades artísticas para enseñar a los que no saben pintar o hacer diseños de figuras, a concentrarse en una actividad y a terminar lo que inicia bajo el principio de ser perseverante.

Con la investigación y los materiales preparados, se inicia el tiempo de la confección de la maqueta para el cual se establece un horario que debe ser respetado y en el que cada miembro del grupo debe dar su aporte. La fecha de finalización de la obra es el día 14 de setiembre a medio día porque a las 6:00 PM, luego del canto del Himno Nacional, se procede a la exposición del proceso de confección, así como a las dificultades encontradas, los logros obtenidos, pero principalmente se expone el aprendizaje adquirido para el proceso de rehabilitación personal y grupal. A continuación, se ilustran las maquetas ya terminadas

Imagen 5. Maqueta alusiva a la provincia de San José

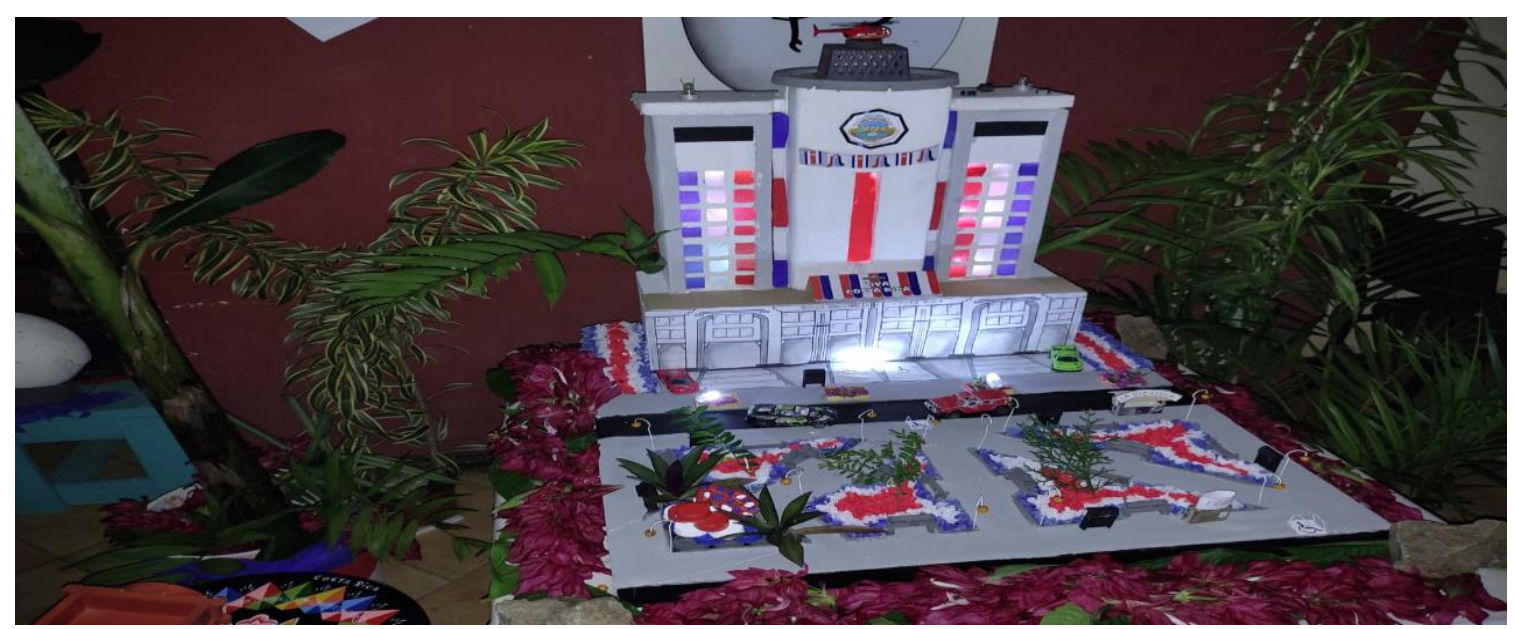


Revista Herencia, Vol. 35 (1), enero-junio, 2022.

Fuente: Asociación Rostro de Jesús 2021

La imagen 5 expone la maqueta alusiva a la provincia de San José, en específico el edificio del Banco Nacional y un detalle del parque que está a la par de Banco Central. Los usuarios que realizaron esta maqueta frecuentaban las cercanías de la zona ilustrada.

Imagen 6. Maqueta alusiva a la provincia de Alajuela

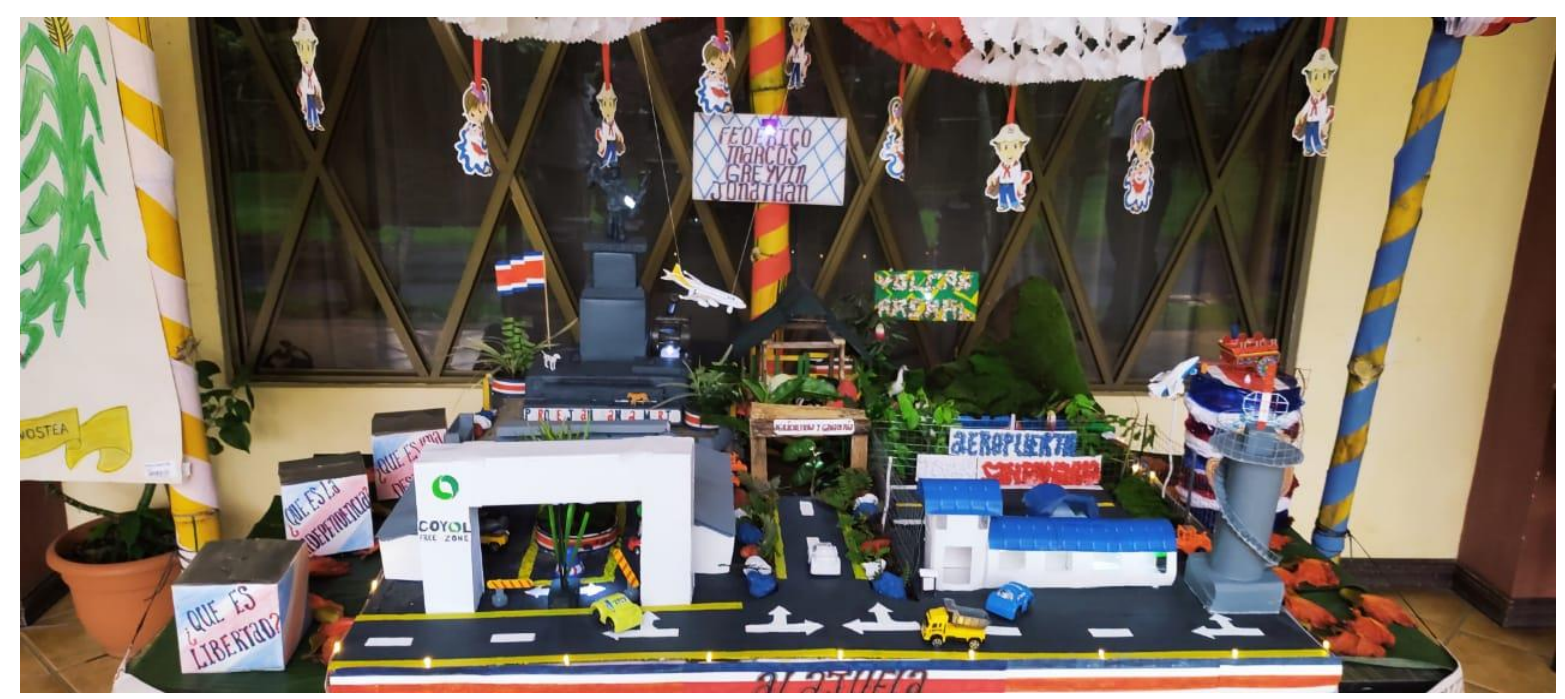

Fuente: Asociación Rostro de Jesús 2021

La imagen 6, correspondiente a la provincia de Alajuela, resalta cuatro elementos: el desarrollo económico de la zona del Coyol, la imagen de Juan Santamaría (héroe nacional), el aeropuerto Internacional y la zona norte de la provincia con los colores verdes y las figuras del parque de Zarcero. Téngase presente que estos lugares son también frecuentados por quienes confeccionaron esta manualidad.

Imagen 7. Maqueta alusiva a la provincia de Cartago

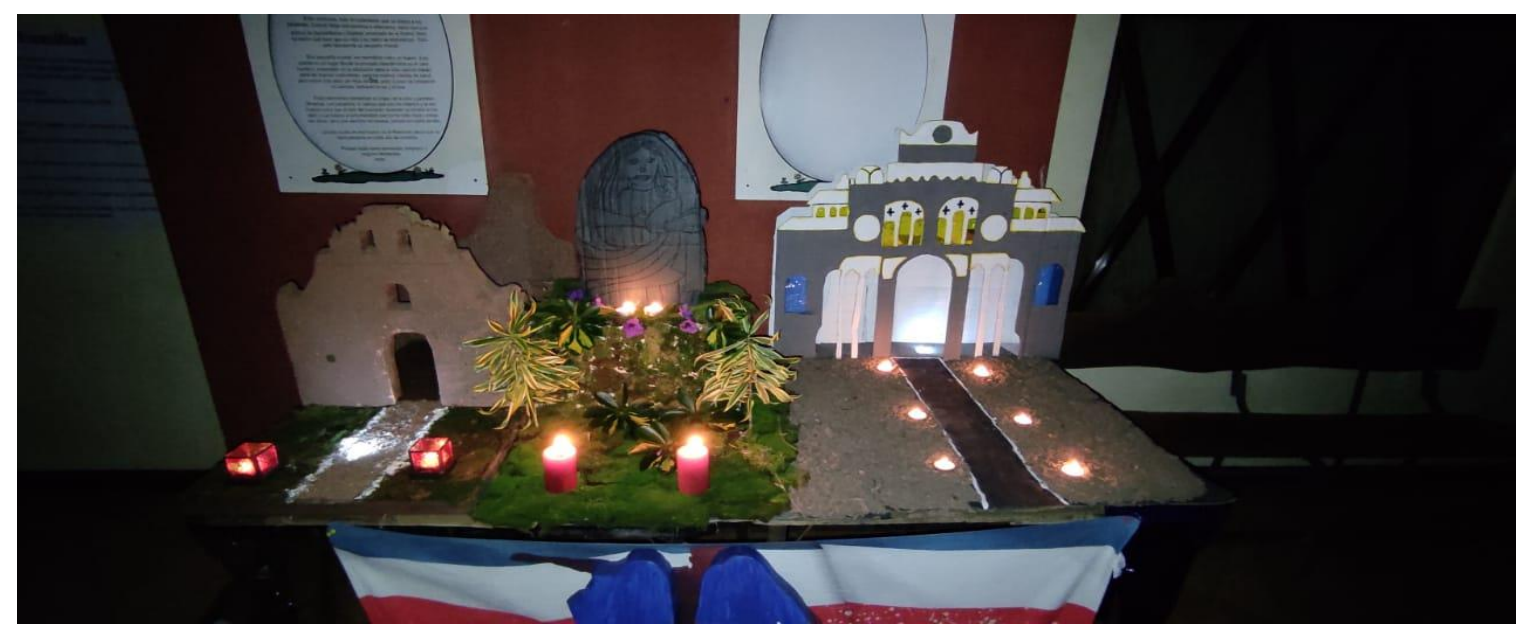

Fuente: Asociación Rostro de Jesús 2021 
En la imagen 7 se expone la maqueta que representa a la provincia de Cartago por medio de la fachada de las ruinas de Ujarrás, la imagen de la Virgen de los Ángeles, y la fachada de la Basílica de Cartago. Los usuarios escogieron estas figuras porque a inicios de agosto se realizó un paseo por la zona, la cual muchos no conocían.

Imagen 8. Maqueta alusiva a la provincia de Heredia

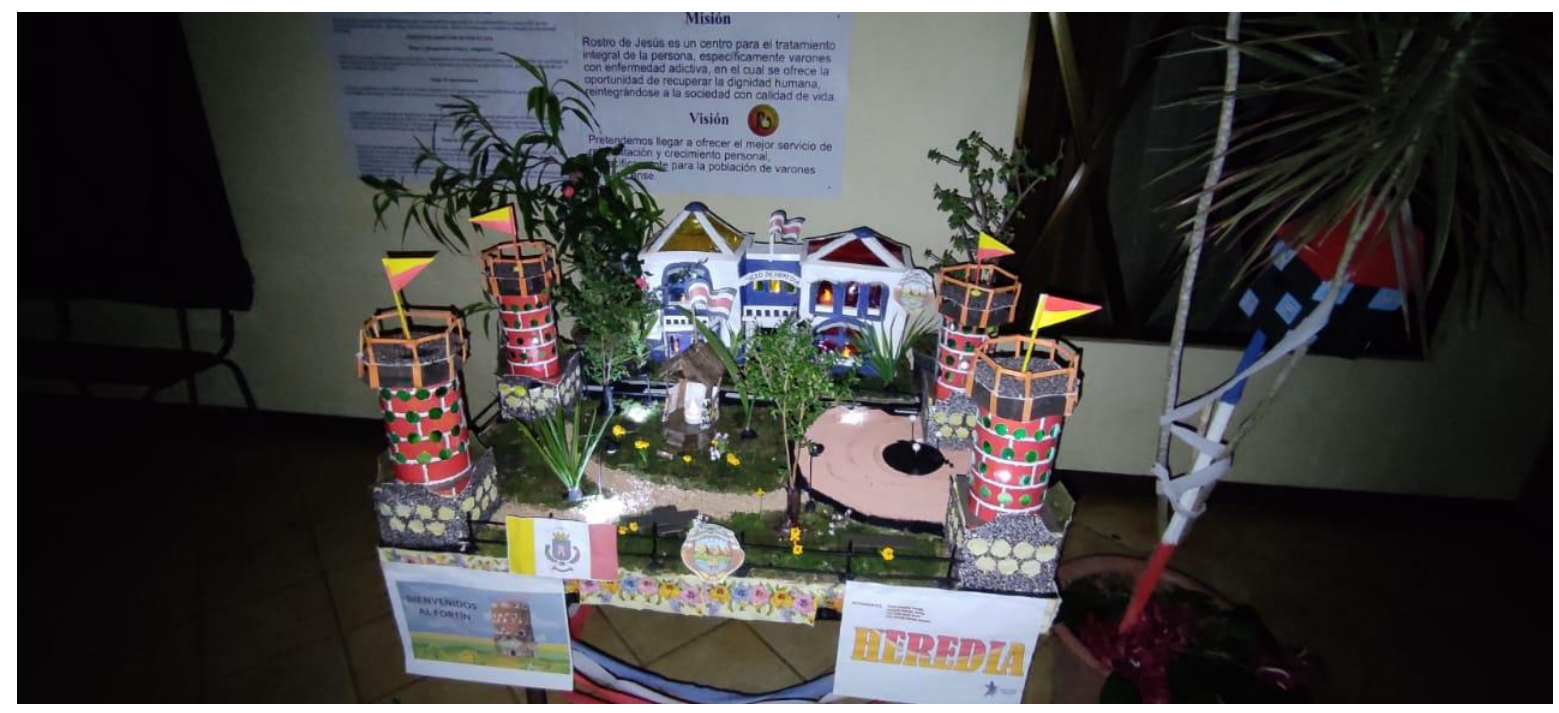

Fuente: Asociación Rostro de Jesús 2021

Esta imagen, llamada 8, representa las torres del Fortín que simbolizan la provincia de Heredia; además, hay un detalle del Parque Central y de edificaciones de la provincia. Los centros urbanos son frecuentados por personas con problemas de consumo de drogas, y Heredia no es la excepción.

Imagen 9. Maqueta alusiva a la provincia de Guanacaste

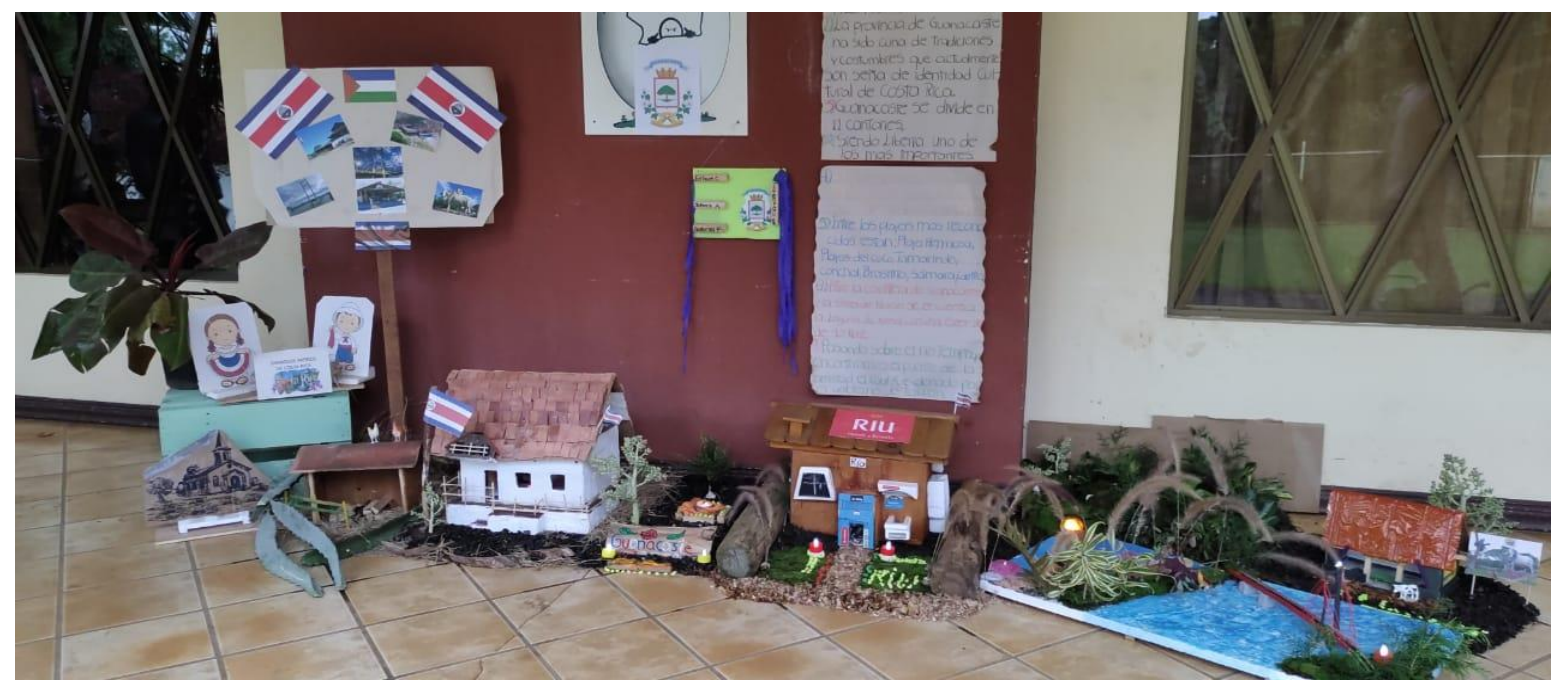

Fuente: Asociación Rostro de Jesús 2021 
En la maqueta que se relaciona con la provincia de Guanacaste (figura 9), se expone el proceso de transformación de la zona, pero conservando todo su sentido cultural. Se observa la típica casa de la zona, la representación de La Casona de Santa Rosa, que recuerda la gesta heroica del año 1856, el desarrollo turístico y la belleza de las playas. Se representa tanto el patrimonio cultural como el patrimonio ambiental y turístico.

Imagen 10. Maqueta alusiva a la provincia de Puntarenas

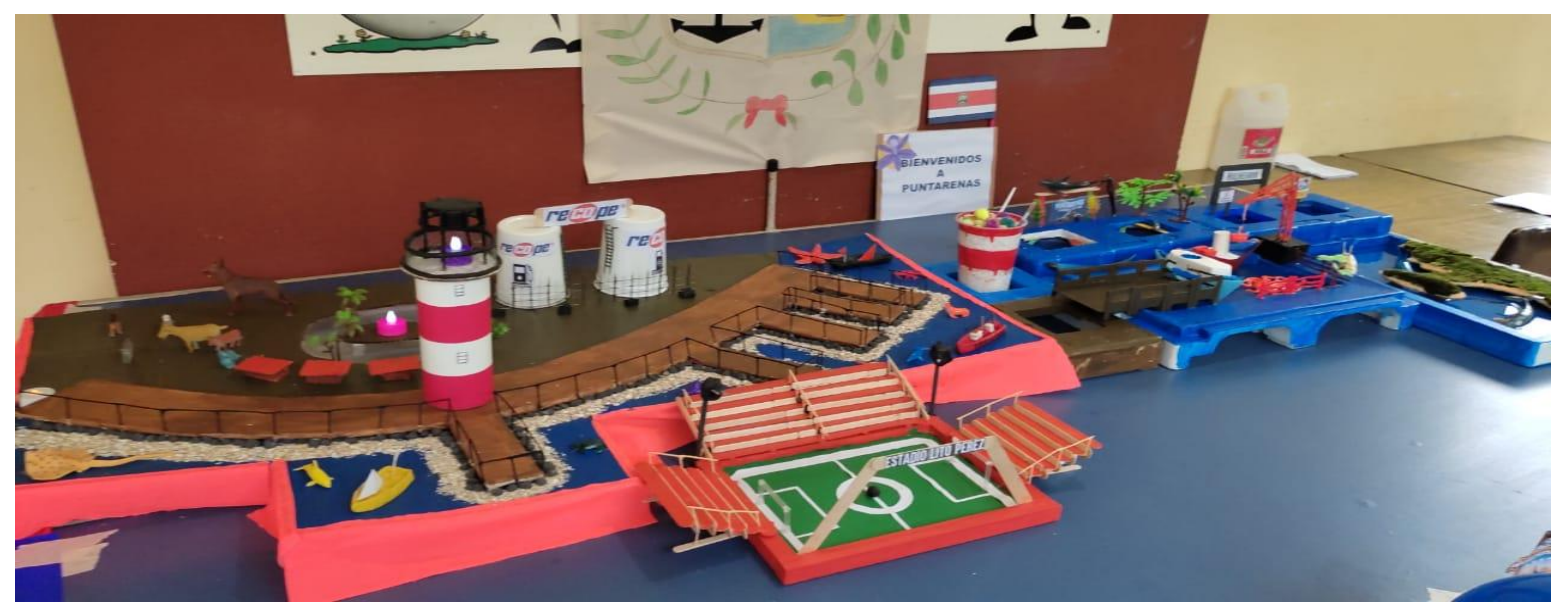

Fuente: Asociación Rostro de Jesús 2021

El Patrimonio Cultural representado en la maqueta alusiva a la Provincia de Puntarenas (imagen 10), ofrece detalles muy significativos de la provincia: el color azul del esplendoroso mar, el faro que engalana la punta de la ciudad, el mítico estadio de Puntarenas, conocido como la olla mágica, el indiscutible Churchill, y el desarrollo económico de la zona representado en el Puerto de Caldera.

Imagen 11. Maqueta alusiva a la provincia de Limón

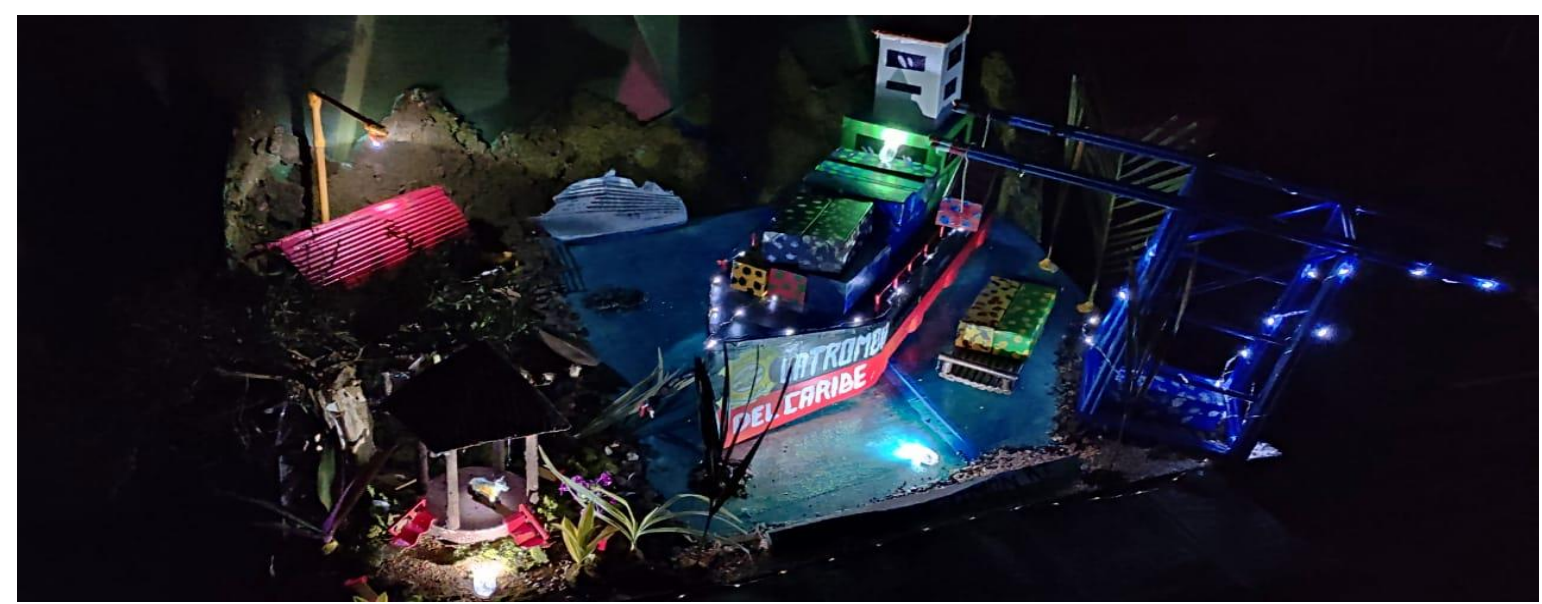

Fuente: Asociación Rostro de Jesús 
Revista Herencia, Vol. 35 (1), enero-junio, 2022.

La sencillez de la maqueta de la imagen 11 no quita la riqueza, la gentileza, la alegría y el deseo de superación de la provincia de Limón, lugar del principal puerto marítimo para el comercio, tanto de Costa Rica como de Centroamérica. Se ilustran detalles como la terminal de contenedores, la llegada de cruceros con turistas de diversas nacionalidades y, sin duda, la riqueza de la bio-diversidad que es un gran patrimonio que se debe preservar y cuidar.

En la evaluación de la experiencia de incorporar el patrimonio cultural en el programa de rehabilitación a través de la confección de las maquetas, arriba ilustradas, los usuarios consideran que mejoraron como personas ya que se dieron cuenta de la capacidad creativa que tienen, aprendieron a valorar el lugar donde nacieron y expresan que es un programa en el cual no son etiquetados como "vagos o delincuentes", sino que más bien son tratados con dignidad humana.

\section{Conclusión}

Por más 18 años, en los que centro de rehabilitación Rostro de Jesús ha incorporado la educación, el aprecio y la conservación del patrimonio cultural mediante actividades de producción artística, como lo es el caso de la confección de maquetas alusivas a paisajes, símbolos y lugares emblemáticos de la historia de Costa Rica, se comprueba que es un recurso pedagógico para el desarrollo de los valores e identidad de las personas, pero también es impulso para la educación de habilidades como:

El trabajo en equipo que fortalece las relaciones humanas mediante el respeto de los diferentes criterios al desarrollar un proyecto común. Esto trae como consecuencia que el usuario del proceso de rehabilitación se vaya preparando para integrarse a la comunidad donde vive poniendo al servicio de ella sus capacidades para mejorar el ambiente donde se habita.

La perseverancia que conlleva aprender a ser paciente con la finalidad de crear un proyecto personal de vida. El patrimonio cultural le permite al usuario reflexionar sobre su actitud de gratificación inmediata o el deseo de vivir de forma instantánea dejando la consideración de que en la vida hay un orden establecido que se hace realidad en el presente. Además, la habilidad de la perseverancia le ayuda a educar la ansiedad y la frustración que son dos de las causas del alto consumo de drogas.

La habilidad de recrear, que se demuestra en el desarrollo de actividades patrimoniales culturales, posibilita en el usuario la capacidad de admiración que es condición necesaria para pensar o filosofar que, a su vez, es principio del deseo de aprender y promueve la actitud del uso de la razón antes que actuar de manera impulsiva o agresiva.

El patrimonio cultural ha demostrado ser un recurso pedagógico muy importante en el desarrollo del programa de rehabilitación, porque el usuario evidencia, con hechos reales, su capacidad creativa, recupera el aprecio por el trabajo, experimenta lo bello o lo que es lo mismo que decir que tiene la experiencia sensible del bien, aprender a reconocer y respetar los límites o las normas sociales y se da cuenta del valor que tiene ser y vivir como costarricense. 
Revista Herencia, Vol. 35 (1), enero-junio, 2022.

En resumen, el patrimonio cultural en la rehabilitación de personas con problemas de adicción a las drogas es un recurso pedagógico (no una medicina mágica) entre otros elementos que contiene un programa de rehabilitación, por el cual se restaura la belleza de la dignidad humana y, además, el patrimonio cultural "contribuye a la cohesión social fomentando un sentimiento de identidad y responsabilidad que ayuda a los individuos a sentirse miembros de una o varias comunidades y de la sociedad en general" (Fontal, 2012, p. 137).

\section{BIBLIOGRAFÍA}

Alberti Manzanares, P. (2010). Género, identidad y patrimonio. México D.F, México: Plaza y Valdés, S.A. de C.V. https://elibronet.ezproxy.sibdi.ucr.ac.cr/es/ereader/sibdi/38917? pp. $69-87$.

Cañas, J. (2008). Antropología de las Adicciones. Sociedad y familia, (4), Roma, Italia. (pp. 1 - 4).

Fontal Merillas, O. (2012). La educación patrimonial: del patrimonio a las personas. Gijón, Spain: $\quad$ Ediciones Trea. https://elibronet.ezproxy.sibdi.ucr.ac.cr/es/ereader/sibdi/60522

García Cuetos, M. P. El patrimonio cultural: conceptos básicos. Zaragoza: Prensas de la Universidad de Zaragoza, 2014. p. https://elibronet.ezproxy.sibdi.ucr.ac.cr/es/ereader/sibdi/42282?

Hernández Hernández, F. El patrimonio cultural: la memoria recuperada. Gijón (Asturias): $\quad$ Ediciones $\quad$ Trea, 2012. p. https://elibronet.ezproxy.sibdi.ucr.ac.cr/es/ereader/sibdi/158769?

Leyva Noa, J. J. (2015). El Patrimonio Cultural Indígena Como Fuente De Sentido Común Desde La Perspectiva De La Participación Comunitaria en Majayara. Revista Panorama, 9(16), 7890. https://doi.org/10.15765/pnrm.v9i16.638

Maraña, M y Revert Roldán, X. (2020). Patrimonio Cultural y Desarrollo: una mirada a la Agenda 2030 y el rol del patrimonio. Periférica, 21, 180-195. https://doiorg.ezproxy.sibdi.ucr.ac.cr/10.25267/periferica.2020.i21.15

Mora Solera, G. (2018). Programa de atención al adicto, Rostro de Jesús. Alajuela, Costa Rica. Sin publicar.

Pérez, E. Amescua, C. y Arizpe, L. (Coord.). El patrimonio cultural cívico: la memoria política como capital social. México D.F: Editorial Miguel Ángel Porrúa, 2011. p. https://elibro-net.ezproxy.sibdi.ucr.ac.cr/es/ereader/sibdi/ 
Revista Herencia, Vol. 35 (1), enero-junio, 2022.

Sissa, G. (2000). El placer y el mal. Filosofía de la Droga. Barcelona.: Ediciones Península.

UNESCO (1982). Declaración de México sobre las Políticas Culturales. Conferencia Mundial sobre las Política Culturales. México del 26 de julio al 6 de agosto de 1982. (p. 1-6).

UNESCO (2021). Patrimonio: Índice de desarrollo de un marco multidimensional para la sostenibilidad del patrimonio. https://es.unesco.org/creativity/sites/creativity/files/digitallibrary/cdis/Patrimonio.pdf 
Revista Herencia, Vol. 35 (1), enero-junio, 2022. 